\title{
Syntactic Features of English Idioms
}

\author{
Gunel Izzaddin Yusifova ${ }^{1}$ \\ ${ }^{1}$ Department of English History and Lexicology, Azerbaijan University of Languages, Baku, Azerbaijan \\ Correspondence: Gunel Izzaddin Yusifova, Department of English History and Lexicology, Azerbaijan \\ University of Languages, Baku, Azerbaijan. E-mail: gunel.yusifova@yahoo.com
}

Received: March 10, 2013 Accepted: April 27, 2013 Online Published: May 23, 2013

doi:10.5539/ijel.v3n3p133 URL: http://dx.doi.org/10.5539/ijel.v3n3p133

\begin{abstract}
Idioms are the expressions the elements of which cannot be changed or replaced by other elements. They are called fixed expressions. However, some changes are possible within idioms. These changes may be both lexical and grammatical.

The acticle deals with the syntactic features of idioms, possible transformations within idioms. Besides, the essential point in the article is to understand why some idioms undergo transformations, while the others don't. Semantics and syntax are taken as a whole in the system of the English language, and the research is carried as to the mutual relationship between them. Different linguistic and cognitive approaches by different scholars have been analyzed in the article, and the proper conclusions have been made.
\end{abstract}

Keywords: syntactic features, form and meaning, unity of semantics and syntax, idioms and non-idiomatic expressions, idioms in the passive voice, transformation within idioms

\section{Introduction}

"Language is a source of misunderstandings" (Antoine de Saint Exupery). People express and share their thought and emotions, their wish and intentions by using the language. Syntax combines words in a sentence; however knowledge of grammar is not good enough to know a language as a whole because language contains lots of idiomatic constructions which require both theoretical and practical knowledge.

The main goal of the article is to seek out ways of understanding the possibility of transformations in some idioms and stability of the others which do not undergo any changes. Different viewpoints have been considered in writing the article some of which have found their reflections in a variety of scientific publications. We have come to the conclusion that the unity of semantics and syntax helps to understand and analyze idioms efficiently. Attempts have been made to discover the relation between form and meaning and define the possible syntactic changes, transformations within idioms. Moreover, the syntactical analyses are carried out from the cognitive point of view.

\section{Research Methodology}

The paper aims at investigating syntactic features of idioms in which the ties between syntax and semantics are essentially focused. As a method of investigation transformational approach is highlighted. Transformations within idioms are considered and explained not only grammatically, but also from the cognitive point of view.

\subsection{The Unity of Form and Meaning in Idioms}

Unless any grammatical form predicts of what a meaning consists, it means that the very grammar form differs from the language rules which we establish a sentence, and the one not corresponding to the grammar rules turns to an exceptional form. In this case it should be learned and investigated as a whole construction. Existence of such constructions is the main condition of the existence of combinations which we call idioms.

We should mark that syntax establishes the coordinated system of form and meaning. Any thought in the language can be expressed in different forms. Sometimes two semantic descriptions in a sentence appear: real or concrete, idiomatic or figurative. Without depending on the sameness of the syntactic structure, the carried out analysis in the same sentence basing on the context shows itself differently. As a result of this, the same form, the same syntactic structure attains different meanings. We may describe the connection of form and meaning in syntax on the example of the idiom He kicked the bucket ("to die") as follows: 


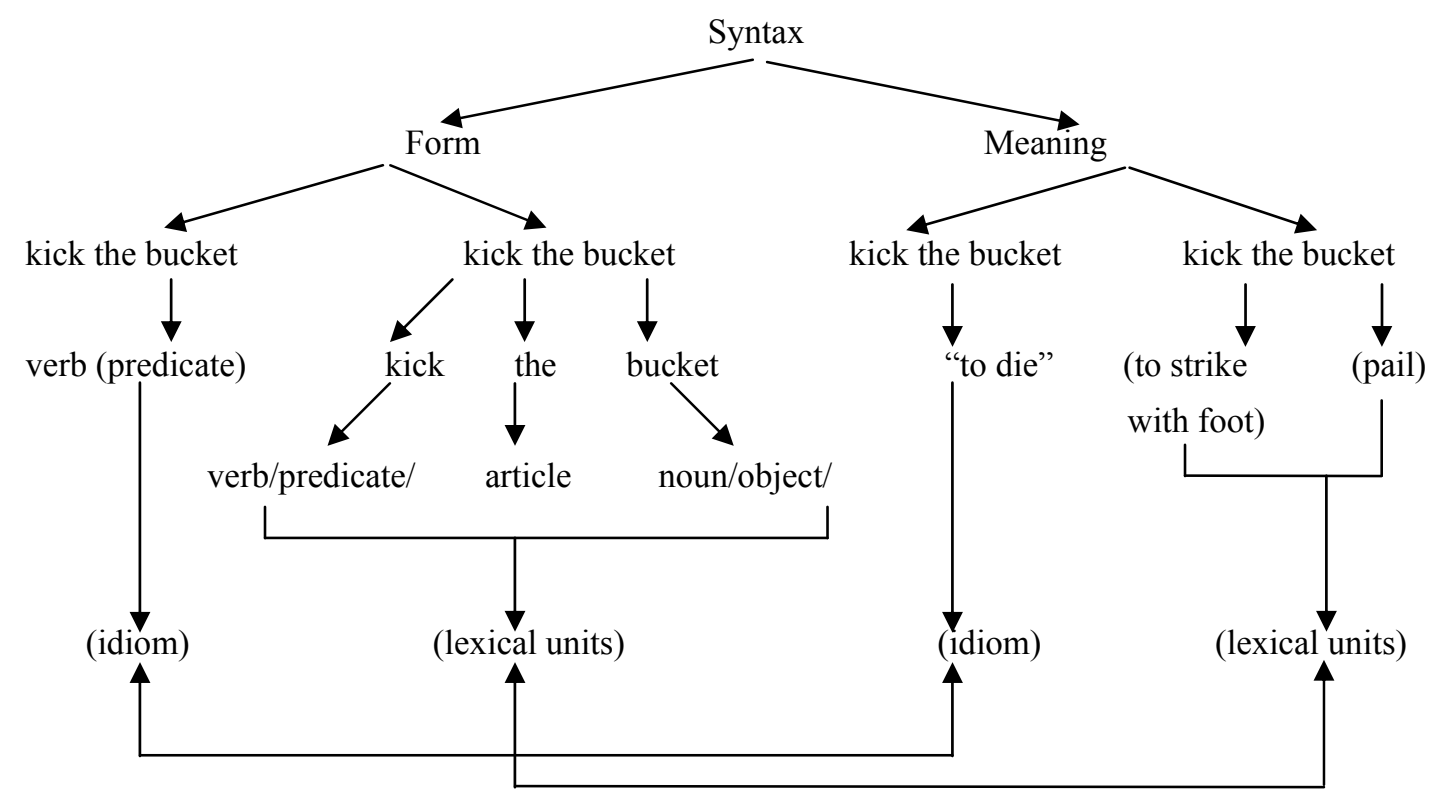

As it is obviously seen, within the sentence (He kicked the bucket) depending upon the form the words possess distinctive syntactic functions.

While describing an idiom its internal specific features must be taken into consideration. The element of idioms cannot be regarded as lexical units. The function which an idiom carries out within a sentence is equal to the function of a single word in the sentence. As an ordinary word an idiom can't be broken into parts in a sentence, neither can be changed. Despite this, it is possible to create a new lexical unit from the words, but on the ground of idioms new combinations cannot be established. Words possess independent meanings, but as the words constituting idioms lose their independence of meaning, the meaning of idioms is not given in the separately-taken words, but the whole idiom expresses the meaning as that of one word. A word is an ordinary realization of meaning, but an idiom is its figurative expression. Words united with one another may form a compound, but it doesn't mean that any compounding is an idiom.

The form, syntactic features and meaning are what make lexical units and idioms identical. Idioms differ from lexical units only in not possessing morphological structure as the construction is taken as a whole.

Highlighting all these features, we stress the fact that during the general analysis of a sentence containing an idiom the whole idiomatic construction must be analyzed as a single word, and question to the whole construction must be put just in the same way as the question directed to a word. Without depending on the number of the words in the sentence, the unity of the syntactic function of an idiom is the major feature characterising it. So, we may name the idiom as a syntactic unit, possessing lexical wholeness. Such syntactic units belong to phraseology and are studied within phraseology.

\subsection{Syntactic Changes within Idioms}

Though the analysis of separately-taken constituent parts of idioms is impossible, the grammar features in them should be kept in view. In many cases the syntactic characterization of idioms has been a subject of dispute. Idioms are classified by different linguists differently, for example, Chomsky (Chomsky, N., 1980) approached the idioms as combinations consisting of constructions, containing logical units. As to Chomsky's considerations some combinations having found their reflection in the human thought should be learned as supplements entering the grammar consisting of certain elements and constructions.

Chomsky (Chomsky, N., 1965, p. 320) sought out a still easier grammar means always able to describe all the sentences. His methods to describe all the sentences by the help of forms have been the main direction of his investigation. Idioms in Chomsky's theories, violating the distribution of grammatical morphemes are viewed as extra-linguistic features, consisting of certain constructions.

Fraser (Fraser, B., 1970, p. 33) has specified the idioms between those which are able to undergo all the grammatical changes and those which are unable to undergo the smallest grammar changes at all.

It should be marked that the development of idioms, their wide usage is a rapid process. They are expressions, not subjected to analysis, only some syntactic changes may be carried out in them. The idioms which can easily 
be subjected to syntactic changes are more flexible. The usage of different grammar tenses within the idioms, the usage of moods of the verb (active, passive voices), change of places of words, inclusion of additional words or reduction of the words within the constructions are the criteria causing difficulties in the investigation of the idioms.

Tense changes within idioms can be possibly made in most of the idioms, for they indicate the animation of the actions in different tenses on the person's mind.

Well, the best way to understand a man is to put yourself in his shoes. (Maugham W.S., The Painted Veil)

Vanished into thin air, just like her four friends. (Cornelia Funke, The Thief Lord).

Italian-Americans here say they fear they have been made a scapegoat. (Ethel Tiersky, Maxine Chernoff, Herald Tribune)

Changes as to singular and plural forms are also possible within idioms; but not all the idioms undergo these changes, i.e. in the idioms smell a rat, kick the bucket, chew the fat the plural forms of buckets, rats, fats are irrelevant. But both idioms can be subjected to tense changes. Adequately, unless in some idioms the plural form is impossible, singular form may also be impossible in the others (spill the beans, rain cats and dogs).

In some idioms the words can be used both in plural and in singular, besides, countable nouns can become uncountable ones and vice-versa. For example: wear the deck - wear the decks, go into detail - go into details, in deep water - in deep waters, kid stuff - kids'stuff, on bended knee - on bended knees, a red herring - red herrings, etc.

It should be noted that the changes as to the tense forms and as to the number appear as minimal changes in idioms. The syntactic transformations occuring in idioms are the problems we cope during the process of their investigations. Some scholars, like Katz (Katz, J., 1973), Weinreich (Weinreich, U., 1969) suggested marking idioms with "+", "-" according to the transformations.

One of the features arousing our interest in the investigation of idioms is that some combinations can be used in the passive voice as non-idiomatic expressions while others cannot.

Weinreich (Weinreich, U. 1969), Nunberg (Nunberg, G. 1978), Gibbs and Nayak (Gibbs, R. and Nayak, N. 1989), Newmeyer (Newmeyer, F. 1974), Chafe (Chafe, W. 1970) and others have highlighted valuable thoughts in characterizing the differences and similarities of idioms and non-idiomatic expressions from the view of the syntactic features.

Newmeyer (Newmeyer, F. 1974) in his investigations defines the importance of the paraphrase in the analysis of the idioms. As to him, idioms accord with their non-idiomatic paraphrases. Nunberg (Nunberg, G. 1978) and Gibbs (Gibbs, R. 1980; Gibbs, R. and Nayak, N. 1989) on the other hand, suggest understanding idioms according to the constituent parts. Their viewpoints show that idioms are partly analyzable, thus, if the elements of idioms help to understand its whole meaning, then they have syntactic flexibility. This approach is cognitive.

The investigations are distinguished by the richness of their varieties. Trying to keep many of such investigations in the highlight, we'll try to throw light on the problem.

Let's pay attention to the usage of idioms in the passive voice within generative grammar. In the generative grammar a sentence does not consist of any groundless individually-taken words. They are combined to form meaning. If we draw the scheme of an ordinary sentence,

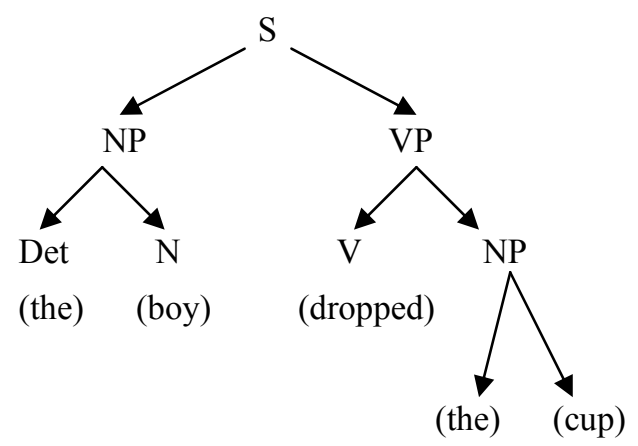

then we shall have to substantiate on the following rule:

$\mathrm{S} \rightarrow \mathrm{NP}$ VP

$\mathrm{VP} \rightarrow \mathrm{VNP}$ 
$\mathrm{NP} \rightarrow$ Det. N

Distribution of words by this order establishes real sentence, and here the meaning of constituent parts of the sentence determines the meaning of the whole sentence. In such constructions the usage of the passive voice creates no difficulty. However, in the sentences possessing idiomatic composition, this description appears in a different form:

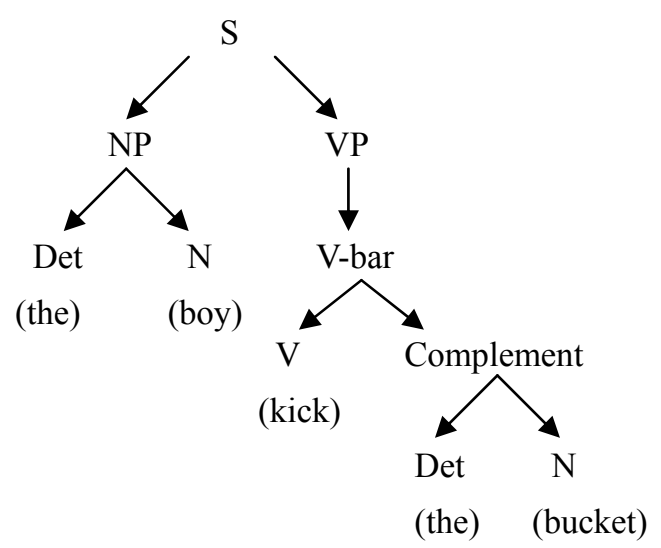

According to the structure the change into passive is impossible (the bucket was kicked). This feature indicates the stability of idioms, their being fixed expressions. However, as the nature of idioms is different, in English this is not exceptional that some of the idioms (as spill the beans, break the ice, bury the hatchet, pay the piper) can be used in the passive voice.

The question arises why some idioms undergo modifications, transformations, but the others do not. Basing on the following sentences, we'll try to explain our opinion in this aspect:

"Oh, yes, Charlie Townsend will get to the top of the tree all right" (Maugham W. S., The Painted Veil).

"He strutted like a peacock through the auditorium while Hornet and Mosca woke the others" (Cornelia Funke, The Thief Lord).

All I need is a shower and a good night's sleep and I'll feel like a million dollars. (http://idioms.thefreedictionary.com/like+a+million+dollars)

Viewing each idiom separately, we shall see that they are the idioms with VP structure. If concentrated on NP-s existing these structures (top of the tree, peacock, million dollars), we may have the thought on the possibility of the usage of the passive voice in a number of idioms. We can explain our opinion in this way: basing on conceptual metaphors (Lakoff, G., 1980), metonymies and the encyclopedic knowledge of the human being (Kovecses, Z., Szabo, P., 1996) the meanings of the idioms can be interpreted. Thus, the image which NP arouses in the idiom reflects the conveyed meaning. In the case when the image, the aroused domain accords with the existing meaning of NP, the idiom accepts transformation as an analyzable construction. If it is impossible to determine NP in the idiom, such constructions can't be subjected to the transformation in the passive voice. The idiom kick the bucket does not awoke "death" domain. The bucket which is NP of the idiom does not agree with "death" imagination. There is not any subsidiary sign to determine NP. In such a case the whole construction won't change into passive voice. This is a cognitive view on the idioms. The idioms like chew the fat = "chat", shoot the breeze = "chat" having the same features belong to this type as well. They can't be analyzed as to the constituent parts; therefore, their transference into the passive voice becomes impossible. Besides, on the other hand, the fact that the paraphrases consist of intransitive verbs attracts the attention. Idioms having intransitive paraphrases are not used in the passive voice.

In the idioms given above, when viewing NP-s we see that the words as top of the tree, peacock, million dollars express figurative meanings. The image aroused by the domain hints to the meaning of the idiom.

In understanding the domains Fillmore's (Fillmore, C. 1982) Frame Semantics comes to our help:

Top of the tree - the image, domain is reaching the highest place, position, rank;

Peacock - explaining metaphorically the character of a vain person by transferring the meaning.

Like a million dollars - the aroused domain is happiness of the person who finds or gets that amount of money.

Also, if analyzed, mostly idioms sound with their paraphrases. Such idioms can be subjected to the syntactic 
variations:

Get to the top of the tree = reach the highest rank;

Strut like a peacock = display oneself like a vain person, exhibit oneself vainly.

Feel like a million dollars $=$ feel very happy, extremely good .

As one change is possible in this type of idioms, they can be subjected to other syntactic variations too: permutations, substitution of words, addition of words are also possible within idioms. However, it should be taken into consideration that any change in the composition of idioms is acceptable in the case if the made change does not affect the meaning of the idiom.

All these possibilities show if syntax and semantic are viewed in relation to one-another, better results could be attained. The unity of syntax and semantics has widely found its wide consideration in Fillmore's works. He considers semantics as a constituent part of syntax.

So, basing on this investigation, we can divide verbal idioms into two groups: the ones not being able to separate as to the constituent parts (idioms as kick the bucket, face the music), and the ones which can be separated as to the constituent parts (such as make someone's blood boil, spill the beans, put on airs, etc). Idioms belonging to the first group are syntactically frozen idioms (fusions). For example, the component bucket within the expression kick the bucket does not possess any individual meaning, therefore, cannot include any element inside (kick the yellow bucket). But the idioms of the second group possess more syntactic flexibility. The constituent parts to some extent possess individual meaning. Of course, these meanings are not the literary meanings of the components. Though the notion expressed by the words of the construction is figurative, they establish adequacy with the paraphrase. We see connections between the components of idioms and the paraphrase. This connection may be metaphorical, metonymical or based on the encyclopedic knowledge of the human being. This group of idioms can undergo several transformations.

\section{Conclusion}

Summing up all the above-mentioned features, we may note that imposing the idea on the language learners that the idioms have no features of being subjected to any changes, pursues the purpose of their better learning. It is true that some idioms can't be subjected to changes (kick the bucket, chew the fat, red herring), but the existence of those of idioms subjected to both lexical and grammatical changes is the proof of complexity of the language. The analysis shows that idioms used in the passive voice are more flexible, and the other transformations, modifications on them are also possible. Both paraphrasing and cognitive-oriented views can determine the type of the syntactic changes. Such mutual ties between syntax and semantics may act as a major factor in carrying out investigations more efficiently. By giving significance to the role of paraphrase, we can use a number of idioms existing in English in different modifications, depending on our creative purposes; but the ability to understand the cause of transformations, substitutions, permutations and to be able to apply them is possible only by the creative approach to the idioms. So, the syntactic analyses of the idioms should not merely be carried out in the grammatical aspect; we should regard them also psychologically, paying attention to the images, domains which the idioms evoke. The cognitive approach may give us reason to discover more clearly the possibility or impossibility of modifications within idioms and use them correctly.

\section{References}

Chafe, W. (1970). Meaning and the structure of language. Chicago: University of Chicago Press.

Chomsky, N. (1965). Aspects of the Theory of Syntax. MIT.

Chomsky, N. (1980). Rules and representations. New York: Columbia University Press.

Fillmore, C. (1982). Frame semantics//Linguistics in the morning calm: Selected papers from the SICOL-1981. Seoul: Hanship.

Fraser, B. (1970). Idioms within a transformational grammar. Foundations of language, 6, 22-42.

Gibbs, R. (1980). Spilling the beans on Understanding and memory for idioms in context. Memory \& Cognition, 8, 149-156. http://dx.doi.org/10.3758/BF03213418

Gibbs, R., \& Nayak, N. (1989). Psycholinguistic Studies on the Syntactic Behaviour of Idioms. Cognitive Psychology, 21,100-138. http://dx.doi.org/10.1016/0010-0285(89)90004-2

Katz, J. (1973). Compositionality, Idiomaticity, and Lexical Substitution. New York. 
Kovecses, Z., \& Szabo, P. (1996). Idioms: A view from Cognitive Semantics (pp. 326-355). Oxford: Oxford University Press.

Kunin, A. V. (1970). English Phraseology. Moscow.

Lakoff, G., \& Johnson, M. (1980). Metaphors we live by. Chicago: Chicago University Press.

Newmeyer, F. (1974). The regularity of idiom behavior. Lingua, 34, 327-342. http://dx.doi.org/10.1016/0024-3841(74)90002-3

Nunberg, G. (1978). The pragmatics of reference. Bloomington, Indiana: Indiana Linguistic Club.

Weinreich, U. (1969). Problems in the Analysis of Idioms. In J. Puhvel (Ed.), Substance and Structure of Language. Berkeley: University of California Press. 